\title{
MECANISMOS DE GESTÃo AMBIENTAL: DA AVALIAÇÃo À VALORAÇÃo AMBIENTAL \\ MECHANISMS OF ENVIRONMENTAL MANAGEMENT: FROM EVALUATION TO ENVIRONMENTAL ASSESSMENT
}

\author{
Djane de Souza Lima Gonçalves ${ }^{1}$, Tiago Estevam Gonçalves ${ }^{2}$ \\ ${ }^{1}$ Universidade Autónoma de Lisboa (UAL),Lisboa, Portugal \\ 2 Instituto Federal de Educação, Ciência e Tecnologia do Ceará (IFCE), Ceará, CE, Brasil
}

Correspondência para: Tiago Estevam Gonçalves (tiagoestevam@ifce.edu.br)

doi: 10.12957/geouerj.2018.29592

Recebido em: 13 jul. 2017 | Aceito em: 10 mai. 2018

\section{RESUMO}

Este artigo tem como objetivo discutir as abordagens teóricas e metodológicas das ferramentas de gestão ambiental, com enfoque na avaliação ambiental e nos métodos de valoração ambiental com viés da economia ambiental e da economia ecológica. Proposta. Considerara-se que a temática interessa à Geografia, à Economia e à Ecologia, assim como a outros profissionais envolvidos com pesquisas voltadas ao meio ambiente. Parte-se das premissas ecológicas na gestão do meio ambiente, bem como sua aplicabilidade torna-se um instrumento para o tratamento das questões relacionadas à degradação ambiental. Reconhece-se a iminência de medidas que possibilite proteger os ecossistemas, um objetivo que pode ser alcançado através de caminhos que introduzam novos paradigmas e leituras sobre as relações economia-natureza. Deste modo, os estudos sobre os mecanismos que contribuem para uma significativa gestão ambiental precisam avançar e ganhar novos embasamentos. Assim, a incorporação dos conteúdos econômicos e ecológicos contribui para os trabalhos relativos à Gestão Ambiental.

Palavras-chave: Ferramentas de Gestão; Avaliação Ambiental; Valoração Ambiental, Economia e Ecologia

\section{ABSTRACT}

This article aims to discuss the theoretical and methodological approaches of environmental management tools, focusing on environmental assessment and environmental valuation methods with a bias of environmental economics and ecological economics. It was considered that the theme is of interest to Geography, Economics and Ecology, as well as to other professionals involved in research on the environment. Part of the ecological premises in the management of the environment, as well as its applicability becomes an instrument for the treatment of the questions related to the environmental degradation. The imminence of measures that allow to protect ecosystems is recognized, an objective that can be reached through paths that introduce new paradigms and readings about the relations between nature and economy. In this way, studies on the mechanisms that contribute to a significant environmental management need to move forward and gain new foundations. Thus, the incorporation of economic and ecological contents contribute to the work related to Environmental Management.

Keywords: Management Tools; Environmental assessment; Environmental valuation; Economy and Ecology

\section{INTRODUÇÃO}

O processo de desenvolvimento técnico-científico que tem como intuito obter patamares cada vez mais elevados de crescimento econômico, consequentemente esses avanços tecnológicos atrelados ao modelo 
econômico de crescimento atual no uso intensificado e na deterioração dos recursos naturais tem como um dos resultados a geração de resíduos em níveis preocupantes.

$\mathrm{Na}$ atualidade, a mudança ambiental mostra-se generalizada, onde a atuação de novos atores que expressam condutas ecológicas distintas reveladas das variáveis demográficas, comportamentais e econômicas; somados a implementação de escalas e de métricas estão transformando as decisões ambientais. Tais decisões como forma de intervenções provocam uma modificação no sistema ambiental, devido à interconexão existente dos elementos naturais, sociais e econômicos.

Neste contexto, o artigo tem como objetivo discutir as abordagens teóricas e metodológicas das ferramentas de gestão ambiental, com enfoque na avaliação ambiental e nos métodos de valoração ambiental com viés da economia ambiental e da economia ecológica, bem como sua aplicabilidade como instrumento para o tratamento das questões relacionadas à Geografia, à Ecologia, à Gestão Ambiental e suas repercussões na mitigação dos impactos ambientais.

Assim, o trabalho contribui com e para uma visão geográfica de Impactos Ambientais e da Gestão Ambiental, bem como o entendimento e formas de aplicação; de importantes conceitos e questões econômicas ecológicas que vão da Economia Ambiental e da Ecológica.

A gestão ambiental será pensada como um conjunto de princípios, estratégias e diretrizes de ações e procedimentos para proteger a integridade dos meios físico e biótico, bem como a dos grupos sociais que deles dependem. Neste sentido, as ferramentas de estratégias ambientais perpassaram a avaliação ambiental, sendo que se fundamentou na avaliação estratégica, avaliação de impactos ambientais, no ordenamento ambiental e ecológico, na análise do ciclo de vida dos produtos, etiqueta ecológica, ecodesenho e por fim nos métodos de valoração ambiental e ecológica. Neste âmbito, os instrumentos de gestão ambiental são elementos importantes nos debates sobre como responder a processos de mudança ambiental global e seus impactos físicos e humanos.

\section{DIÁLOGOS E PERSPECTIVAS DE MECANISMO DE GESTÃo AMBIENTAL}


A gestão ambiental no exercício de sua função necessita de uma cadeia de ações, práticas e instrumentos que conjugados em congruência contribuem para a prevenção, mitigação e correção dos impactos ambientais. Daí a relevância da premissa que: para uma gestão com significância necessitarse-á de uma minuciosa avaliação ambiental. A avaliação ambiental como integrante da gestão ambiental tem o caráter preventivo e orientador, para evitar que efeitos negativos de uma intervenção no meio ambiente volte a ocorrer (GALLOSO, 2009).

A identificação de impactos, prevenção, mitigação e compensação de impactos adversos, como também a otimização dos impactos favoráveis compõe o papel da avaliação ambiental. Com isto, melhora os fatores éticos, os desenhos, os processos, as correções, as reparações; incluindo a eliminação de riscos ambientais e custos desnecessários, tempo e dinheiro de uma política, um plano, um programa ou um projeto de cunho ambiental.

Na definição do Ministério do Meio Ambiente (2016) brasileiro, os instrumentos de avaliação ambiental são:

- Avaliação Ambiental Estratégica (AAE);

- Avaliação de Impacto Ambiental (AIA);

- Abordagens do componente social na avaliação ambiental;

- Desenvolvimento de propostas de trabalho;

- Desenvolvimento de análise de proposta de novas regulamentações.

Nas descrições do Ministério do Meio ambiente - MMA (2016), a interação destes instrumentos busca a proposição de metodologias e diretrizes para a avaliação ambiental estratégica, a realização de trabalhos técnicos e de articulação setorial para o aprimoramento dos procedimentos para 0 licenciamento ambiental federal e a regularização ambiental de portos, rodovias, dentre outros. E por fim, uma satisfatória articulação do envolvimento de órgãos do licenciamento ambiental.

\section{Avaliação ambiental estratégica (AAE)}


Segundo o Ministério do Meio Ambiente (2016) A avaliação ambiental estratégica (AAE) é uma ferramenta que propicia a adoção das melhores decisões ambientais através da análise de alternativas ou variantes de seus componentes, atividades ou projetos específicos, incluindo os impactos acumulativos de nível local, regional e global. Como política ambiental, o objetivo da AAE é o de assistir previamente os gestores no processo de identificação e avaliação dos impactos, efeitos e, quando possível, otimizar os positivos e reduzir os negativos de determinada decisão estratégica. Destacam-se os seguintes benefícios:

- Uma perspectiva ampla do encadeamento da implantação de políticas de ambiência;

- Seguridade no tratamento de implicações ambientais;

- Compreensão do processo de formulação de política e planejamento integrado e sustentável;

- Antecipação dos prováveis impactos de intervenções;

- Melhor contexto para avaliação de impactos ambientais cumulativos, dentre outros.

\section{Avaliação de impactos ambientais (AIA)}

Na resolução do Conselho Nacional do Meio Ambiente - CONAMA n 001 de 23 de janeiro de 1986, o impacto ambiental é considerado como qualquer alteração das propriedades físicas, químicas e biológicas do meio ambiente, produzido por qualquer forma de matéria ou energia consequente das ações antrópicas que direta ou indiretamente acometam a saúde, a segurança e o bem-estar da população; as atividades sociais e econômicas; a biota; as condições estéticas e sanitárias do meio ambiente e a qualidade dos recursos ambientais.

Em relação à categorização, os impactos estão categorizados da seguinte forma (CONAMA, 1986):

- Impacto ambiental acumulativo - o efeito no ambiente resulta dos incrementos dos impactos de ações particulares ocasionados pela interação com outros passados;

- Impacto ambiental sinérgico - produzido quando o efeito conjunto da presença simultânea de várias ações supõe uma incidência ambiental maior que é a soma das individuais; 
- Impacto ambiental significativo - resulta da ação do homem ou da natureza, provocando alterações no ecossistema e recursos naturais ou na saúde, sendo uma barreira para a existência e desenvolvimento do homem e dos demais seres vivos;

- Impacto ambiental residual - aquele que persiste depois da aplicação de medidas de mitigação.

Neste contexto, a Avaliação de Impacto Ambiental (AIA) é concebida como um processo sistemático para identificar, presidir e avaliar os efeitos e impactos ambientais de ações e projetos, ou seja, é uma tentativa de prevê impactos com informações objetivas (GALLOSO, 2009). Operando com modelos de realidade, com um conjunto de possibilidades de ocorrências de fatos atuais. Os elementos do estudo de impacto ambiental estão especificados abaixo:

- Descrição integral do projeto de obra ou atividade;

- Descrição e avaliação dos distintos projetos alternativos e das alternativas favoráveis;

- Análise das relações entre os custos econômicos e efeitos ambientais de cada alternativa;

- Caracterização da área (fatores ambientais);

- A descrição dos afluentes e emissões estimadas: liquidas, gasosas, sólidas ou combinações destas;

- Descrições das ações que gerarão impactos;

- Identificação e classificação dos impactos;

- Relações ações/impactos;

- Medidas de prevenção, mitigação e correção dos impactos negativos;

- Programação detalhada para vigilância ambiental e monitoramento das variáveis para controlar durante o funcionamento. 


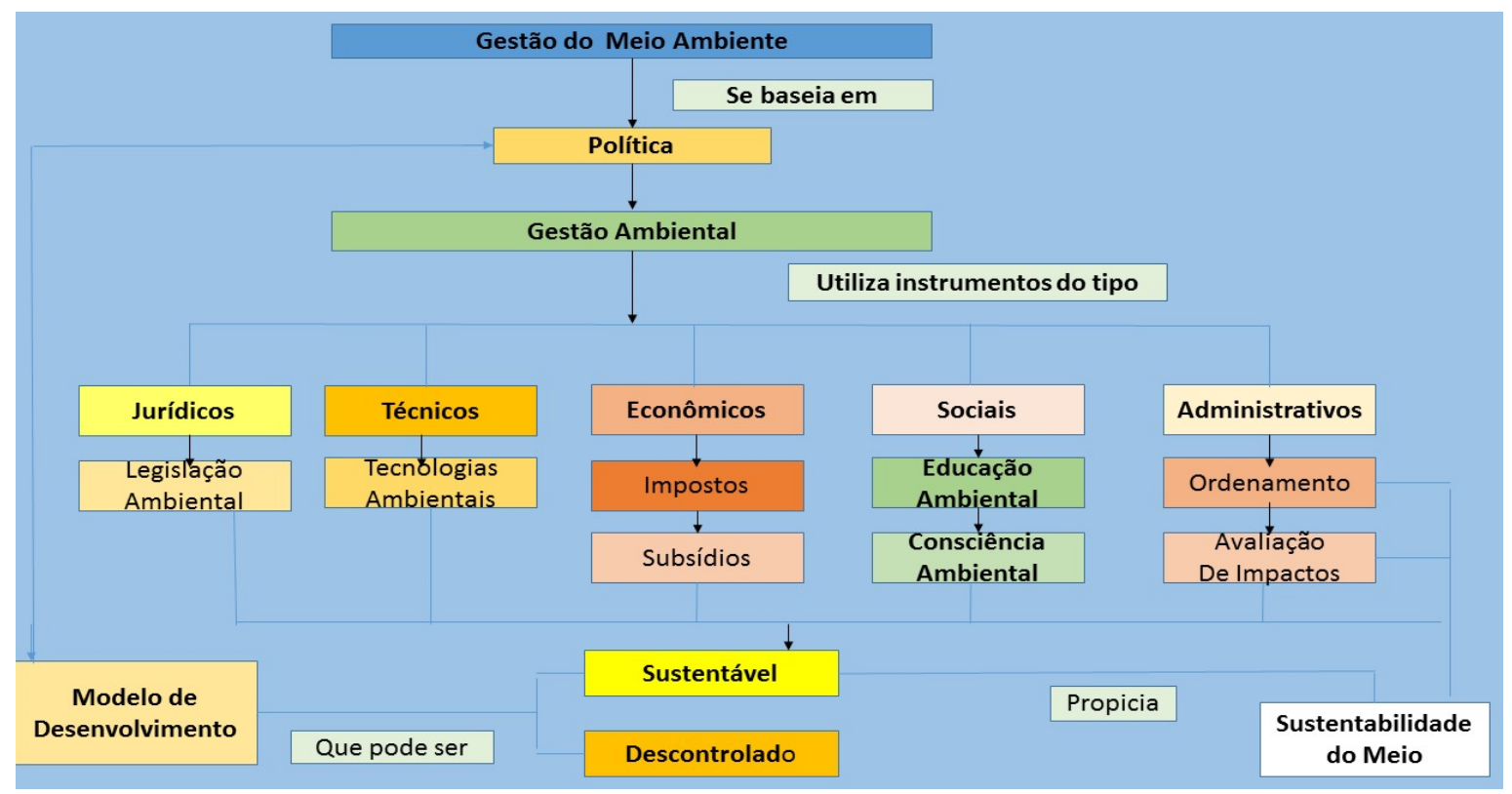

Figura 1. A Gestão Ambiental e seus Instrumentos Fonte: Adaptado de GALLOSO, 2009

\section{Ordenamento ambiental e ecológico}

Ordenamento Ambiental consiste em uma série de análise, processos e manobra que permitem uma utilização adequada do meio ambiente. Com a finalidade de alavancar um desenvolvimento econômico sustentável que satisfaça as necessidades reais da população atual e da geração futura (RIVERO ORTEGA, 2010).

O Ordenamento Ecológico é um instrumento de política ambiental cujo intuito é regular ou induzir o uso do solo e das atividades produtivas, com a finalidade de proteger o meio ambiente e preservar o aproveitamento sustentável dos recursos naturais, a partir de análises das tendências de deterioração e potencialidades de aproveitamento dos mesmos (BRASIL, 1981). Seguintes critérios a considerar no Ordenamento Ecológico:

- A natureza e características dos ecossistemas existentes no território nacional exercem soberania e jurisdição;

- A finalidade de cada zona ou região, em função de seus recursos naturais, distribuição da população e atividades econômicas predominantes;

- Os desequilíbrios existentes nos ecossistemas por ação antrópica ou fenômeno natural;

- Equilíbrio que deve existir entre assentamentos e condições ambientais; 
- Impactos de novos assentamentos, vias de comunicação e demais obras e atividades;

- Se áreas protegidas.

\section{Análise do ciclo de vida dos produtos, etiqueta ecológica e ecodesenho}

Esta análise define-se por ser um processo de avaliação dos aspectos ambientais de um produto por meio das fases do seu ciclo de vida. Como: a extração de matéria-prima, produção, transporte e de distribuição, utilização do produto pelo cliente e vida final útil.

Os principais propósitos desta análise é introdução de melhorias ambientais através de projeto de produto; identificar em qual estágio resultam os principais problemas no meio ambiente; introdução dos critérios ambientais na seleção de fornecedores; comparar a "bondade ambiental" de um produto com a concorrência; observar o impacto no meio ambiente na fase de uso e consumo (informações do cliente); conhecer os impactos do final do ciclo; permitir as ações conjuntas de empresas de um determinado setor; facilitar a obtenção da etiqueta ecológica.

A Etiqueta Ecológica ou Eco Etiqueta é caracterizado pelo selo da Associação brasileira de normas técnicas (ABNT - Qualidade Ambiental) concedidos aos produtos que demonstrem reduzidos impactos ao meio ambiente em suas diferentes fases dos impactos do ciclo de vida, ou seja, esteja em cumprimento aos critérios ecológicos. Tais ferramentas tem como objetivos: promover entre as empresas de design e produção de produtos possam ter um menor impacto no meio ambiente e os níveis necessários de qualidade e segurança, oferecendo aos consumidores uma melhor informação.

A respeito do Ecodesenho ou Design ambiental destina-se ao desenho de produtos e processos para melhorar o impacto no meio ambiente em que empresa desenvolve suas atividades. As utilidades são de agregar valor ao portfólio de produtos como uma forma de inovação; de contribuir para a diferenciação do produto (consumidores "ecológicos"); de obter o reconhecimento da qualidade na sustentabilidade ambiental; de melhorar campanhas de comunicação ambientais; de permitir poupanças de custos; de 
evitar as queixas dos consumidores finais; de permitir antecipar a legislação e de vender o conhecimento adquirido para terceiros.

Neste enquadramento, podem ser introduzidas melhorias ambientais no produto ou processo de produção usando dois pontos de vista: primeiro, as ações de melhoria agrupada de acordo com as fases do ciclo de vida; segundo, usando um conjunto de elementos do meio ambiente.

\section{Métodos de valoração ambiental}

Os métodos de valoração ambiental com viés da economia ambiental e com viés da economia ecológico foram desenvolvidos com o viés de valorar os recursos ambientais e seus serviços devido aos efeitos da interface economia e meio ambiente, cada um com limitações a diversos tipos de problemas e situações. Apresentam-se assim dois grupos de métodos: o primeiro baseado na função utilidade e o segundo em análises biofísicas (MAY, 1996).

O primeiro grupo de métodos de valoração está incorporado à vertente da economia ambiental neoclássica que se coloca como caminho de análise a utilização de instrumentos que tem como base a microeconomia neoclássica, buscando atribuir valores monetários aos bens e serviços do meio natural, vinculados à utilidade derivada. Sendo estes relevantes para determinar os custos e benefícios referentes à aplicabilidade dos serviços ambientais e no que tange ao nível de bem-estar do indivíduo.

No segundo grupo de métodos de valoração, a visão biofísica que vai de encontro à análise da segunda lei da termodinâmica - lei da entropia, o processo de produção econômica é considerado como transformação contínua de baixa entropia em direção à alta entropia compreendida nos desperdícios do final do processo. Significando assim que toda energia utilizada pelo sistema econômico para a manutenção do seu crescimento ressurge irrevogavelmente após a produção sob uma forma degradada, isto é, em forma de poluição. Daí surge à relevância da incorporação das interdependências biofísicas nas abordagens de valoração. 


\section{Métodos de valoração ambiental com viés da economia ambiental}

Motta (2006) ressalva que as técnicas de valoração são classificadas em: métodos indiretos que são métodos da função de produção onde abrange o método de produtividade marginal, os baseados em mercados de bens substitutos (custos evitados, custo de controle, custos de reposição e custo de oportunidade), e os métodos diretos que são métodos da função de demanda, apoiados da disposição a pagar indireta (custo de viagem e preços hedônicos) e na disposição a pagar direta (avaliação contingente). Sendo a escolha do método baseada no proposito da valoração, nas hipóteses assumidas, na quantidade de dados disponíveis e do conhecimento da dinâmica ecológica do objeto que está sendo valorado.

Ortiz (2003) conceitua métodos de valoração indiretos por aqueles que determinam o valor econômico de um recurso ambiental a partir da observação do comportamento do consumidor, sejam em mercados de bens complementares ou bens substitutos.

Maia et al (2004) abordam que um dos métodos de valoração indireto é o método da produtividade marginal. Este método atribui um valor ao uso do ecossistema relacionando a quantidade, ou a qualidade de um recurso natural diretamente à produção de outro produto com preço existente no mercado. Assim estima-se a função dano ambiental ou função Dose-resposta - DR.

A finalidade do recurso natural no processo produtivo será representada pela função Dose-resposta que associa o nível de provisão do recurso ao nível de produção respectivo do produto no mercado. Esta função avalia o impacto no sistema produtivo, dada uma variação marginal na provisão do bem ou serviço ambiental, calculando o valor econômico de uso do recurso com base na variação.

A hipótese básica por detrás da aplicação dos métodos de mercados de bens substitutos é a de que as atitudes dos agentes econômicos podem revelar o valor implícito de características particulares do meio ambiente, possibilitando a valoração das alterações deste com base nas alterações provocadas no valor de bens complementares ou substitutos com preço fixado no mercado (MUELLER, 2007). Evitando 
assim que a receita liquida de uma atividade possa ser afetada pela variação do recurso ambiental, não só pela diminuição da produção, mas também pelo aumento dos custos.

Quando o recurso natural é um insumo ou um substituto perfeito de um bem ou serviço privado, os métodos empregam preços de mercado relacionado a esse bem ou serviços, com base nesses preços, admitindo que estes não se alterem perante a variação de disponibilidade do recurso ambiental, estimam-se indiretamente o valor econômico (preço sombra) dos recursos ambientais cuja variação está sendo analisada.

Algumas técnicas são derivadas dos métodos de mercados de bens substitutos, uma das quais é a de custos evitados ou gastos defensivos, onde, de acordo Ortiz (2003) este método procura estimar os gastos que seriam incididos em bens substitutos para não alterar a quantidade consumida ou qualidade do recurso natural analisado, ou seja, o valor do recurso é calculado por meio dos gastos com operações defensivas através de substitutos perfeitos ou complementares, aproximando-se monetariamente das mudanças destes atributos ambientais.

Em uma das hipóteses deste método, o bem de mercado substituto do ativo natural, deve gerar apenas o benefício de substituir o recurso ambiental analisado sendo seu substituto perfeito. Como por exemplo, o gasto com o acesso de água potável ou com a compra de água mineral por algum indivíduo, supõe-se que este esteja analisando todos os possíveis problemas da água poluída, e indiretamente medindo sua disposição a pagar pela a água saudável. Porém as estimativas dos custos evitados deste método tendem a ser subestimadas devido a não ser considerada uma série de elementos, como alguns comportamentos assimétricos dos indivíduos, além da falta de informação sobre os reais benefícios do bem ou ativo ambiental.

Outra técnica derivada do método de mercado de bens substitutos é a do custo de reposição, esta técnica consiste em mensurar o custo de repor ou restaurar o recurso ambiental prejudicado como uma aproximação da variação da medida de bem-estar relacionada ao recurso ambiental. Seus cálculos são 
apoiados em preços de mercado, partindo do pressuposto que o recurso natural possa ser devidamente substituído.

Apesar da proporção dos gastos envolvidos para restauração do recurso ambiental, nem todas as complexas propriedades de um recurso natural serão repostas pela substituição por outro. Como o restabelecimento de toda biodiversidade existente de alguma floresta nativa depois do desmatamento da mesma. De maneira que nem todas as propriedades do bem degradado podem ser repostas, as estimativas tendem a ser subestimadas, e fornece uma aproximação dos prejuízos econômicos causados pela diferença da manutenção da produção econômica pelo recurso natural. A hipótese de que a variação do preço de mercado do bem ou de seu substituto equivale à variação de seu estoque repercutirá na subestimação da valoração, pois é incerto encontrar esse bem substituto. (MOTTA, 2006).

O método de custo de controle também é derivado do método de mercado de bens substitutos, segundo Maia et al (2004) representa os gastos necessários para evitar alteração do bem ambiental e garantir a qualidade dos benefícios gerados à população. Como o caso do tratamento de esgoto para evitar a poluição dos rios e de um sistema de controle de emissão de poluentes de uma indústria para evitar a contaminação da atmosfera. O controle da degradação contribui para manter um nível sustentável de exploração, permitindo o aproveitamento dos recursos naturais pelas gerações futuras.

As maiores complicações deste método estão relacionadas à estimação dos custos marginais de controle ambiental e dos benefícios gerados pela preservação. Os investimentos de controle ambiental tendem a gerar benefícios diversos, sendo necessário um aprofundamento maior nas pesquisas para determinação de todos estes. Como não há também um consenso quanto ao nível adequado de sustentabilidade, as pessoas encontram sérias dificuldades para ajustar os custos aos benefícios marginais e determinar o nível ótimo de oferta do recurso natural.

Segundo Motta (2006), o método do custo de oportunidade não valora diretamente o ativo ambiental, este calcula o custo de preservá-lo das atividades econômicas que poderiam estar sendo executadas na 
área de proteção, correspondendo assim, as perdas econômicas dos indivíduos em virtude das restrições de uso dos recursos ambientais, ou seja, o custo de oportunidade da renda sacrificada em prol da preservação do recurso ambiental.

Maia et al (2004) argumentam que o caso de um parque ou reserva florestal com a exploração restringida, o custo de oportunidade de sua preservação seria gerado pelos benefícios, provavelmente de extração de madeira. Mas os benefícios ecológicos desta preservação poderiam ser manifestados pela renda gerada em atividades como ecoturismo e/ou aproveitamento de ervas-medicinais. Na estimação dos custos de oportunidade, os danos criados por atividades insustentáveis devem estar incluídos. Pois estes podem ser irreversíveis e reduzir a oferta do bem ou serviço ambiental ao longo do tempo.

Para Ortiz (2003), os métodos de valoração direto baseados na função demanda buscam mensurar as preferências dos indivíduos por bens e serviços ambientais a partir de levantamento de dados que estabeleçam as preferências relacionadas ao bem ou serviço, como por exemplo, entrevista direta com as pessoas. Um dos mais antigos métodos direto é o método de custo de viagem. Seus cálculos procuram examinar uma disposição a pagar (DAP) indireta pelo recurso natural através da estimação dos custos de visitação.

Este método mensura a demanda por uma área ambiental, como patrimônio natural, por exemplo, com base nos custos incorridos dos usuários pelo acesso ao ativo. Esta técnica estipula uma função relacionando o custo de visitação às variáveis (características que interprete a visita ao patrimônio) de custo de viagem.

$\mathrm{Na}$ categoria de métodos baseado na função de demanda também se enquadra a técnica de preços hedônicos que isola as contribuições do meio ambiente utilizando cálculos estatísticos estabelecendo a alteração do valor do ativo. 0 método de preços hedônicos pretende estimar um preço implícito por atributos ambientais característicos de bens comercializados em mercado, através da observação desses mercados reais nos quais os bens são efetivamente comercializados (ORTIZ, 2003). 
Segundo Mueller (2007), as técnicas dos métodos de preços hedônicos isolam os efeitos positivos que o meio ambiente proporciona para o valor de um ativo ou recurso ambiental, partindo-se do pressuposto de que o valor total de um item de patrimônio ou de um recurso ambiental é função de um conjunto de características deste, das quais uma delas está nas condições do meio ambiente. Estatisticamente, o método aplica uma regressão de quadrados mínimos ordinários para ajustar, por exemplo, o preço da residência às diversas características que possam inferir no seu valor.

Outro método baseado na função de demanda é o método de valoração contingente que de acordo com Motta (2006), o método de valoração contingente busca calcular monetariamente, por meio da disposição a pagar (DAP) e da disposição a aceitar (DAA) ou receber (DAR) do indivíduo, o impacto no nível de bem-estar da população resultante de uma variação quantitativa ou qualitativa de disponibilidade dos bens ambientais. Nas estratégias desse método incluem pesquisa de campo para obtenção de características do recurso através da simulação de mercados hipotéticos com a intenção de estimar a DAP e a DAA ou DAR, devido à função utilidade não ser observável diretamente.

Maia et al (2004) afirmam que apenas este método capta valores de não uso de bens e serviços ambientais. E que o método de avaliação contingente é aceito por diversas instituições nacionais e internacionais em vista da avaliação de projetos de grandes impactos ambientais. Por ser flexível e adaptável a quase todos os casos de valoração ambiental.

\section{Métodos de valoração ambiental com viés da economia ecológica}

Um dos procedimentos que faz distinção entre fonte de energia de baixa entropia (tal como energia solar) e as fontes de alta entropia é o método de avaliação exergético. Nesta técnica agregam-se as propriedades qualitativas da energia, em outros termos, considera a primeira e a segunda lei da termodinâmica, quantificando aquilo que é qualitativamente referido como uma deterioração da energia. A exergia é mensurada pela multiplicação do equivalente calor de um combustível ou de uma fonte térmica pelo fator de Carnot correspondente [1-(Ta/To)], onde Ta representa a temperatura 
ambiente e To a temperatura produzida à saída do processo, ambos medidos em graus Kelvin (FAUCHEUX e NOËL, 1995).

As análises dos indicadores fornecidos através dos métodos de avaliação exergético, não são eficientes para outros usos, somente para o trabalho mecânico. Para Patterson (2002), a formula de Carnot é problemática para atribuir valor ao calor devido ao pressuposto da irreversibilidade da segunda lei da termodinâmica.

Atualmente, a análise eMérgetica é que direciona a determinação dos valores ecológicos assentados nas análises energéticas. Odum (1996) introduziu as pesquisas sobre eMergia, definida como a soma de energia disponível já utilizada direta ou indiretamente para criar um serviço ou um produto. Refere-se a um método que busca resgatar toda a memória energética de um produto, por meio de fatores de transformidade antecipadamente calculados, converter todas as formas de energia utilizadas nos seus processos de formação/produção em correspondentes de energia solar (ANDRADE e ROMEIRO, 2009).

Faucheux e Noël (1995) abordam que se todos os recursos energéticos forem normalizados em função da energia solar, a energia aponta como montante de energia que, qualquer que seja a sua natureza corresponda à energia solar requerida para produzi-lo. A técnica de avaliação de eMergética foi utilizada para medir bens e serviços tanto ambientais como econômicos baseados de uma energia da mesma fonte.

Algumas críticas em relação as abordagens metodológicas são assinaladas por Sinisgalli (2006). Para este, por não considerar a variabilidade da transformidade (quantidade de energia solar empregada, direta ou indiretamente, na obtenção de 1 joule de um determinado bem ou serviço) de cada material, dado que a variabilidade está diretamente ligada à cadeia de eventos para sua transformação, ou seja, acerca da estabilidade das transformidade no tempo no espaço. 
Neste sentido, a entropia aponta como um meio de medir as perdas irreversíveis de sistemas energéticos através de indicadores, o potencial; de geração de entropia, calculado a partir de quantidades mensuráveis, que verifica os processos físicos e químicos incontrolados nos sistemas ambientais devido a desperdícios. (FAUCHEUX e NOËL, 1995).

Alier (2013), cita resumidamente alguns métodos contemporâneos voltados para o estudo das tendências no uso de matéria e energia pela economia. Como o estudo do cálculo de fluxo de energia a nível nacional ou regional, esta pesquisa inclui em sua análise mudanças de proporções da utilização de energia exossomática e endossomática, cálculos do EROI (retorno sobre investimento energético). Os cálculos do EROI mostram se há uma tendência no sentido de aumento de custos energéticos relacionada com a obtenção de energia posta à disposição.

Na concepção do método de cálculos do Human appropriation of net primary production em português apropriação humana da produção primária liquida, incluindo o Índice de Pegada Ecológica incorporada, é relevante para as estatísticas do comércio. Nesta análise, quanto maior apropriação de biomassa pelos seres humanos para produção em potencial em uma determinada área, menor a quantidade de biomassa disponível para outras espécies. Provocando provavelmente a perda da biodiversidade. Nos cálculos é incluída a crescente demanda de terra para urbanização e infraestrutura, para a agricultura e agronegócios. Tudo é medido em unidades distintas e podem demonstrar tendências diferentes, embora haja regras de congruência entre estes índices.

Outro método citado é dos cálculos de fluxos de materiais (muitas vezes classificados em biomassa, material de construção, minérios e combustíveis fósseis) medidos em toneladas a nível nacional ou regional. Esta pesquisa testa a hipótese de "desmaterialização" da produção ou do consumo, realizando-se a partir deste método cálculos de comercio físico equilibrados apoiando os argumentos sobre o comércio ecologicamente desigual (RUSSI et al, 2008 apud ALIER,2013). 
Segue como exemplo também o método de cálculos de "água virtual” na exportação ou na importação a nível nacional ou internacional de commodities, como trigo, soja, carne, etanol, celulose, dentre outras. Este estudo preocupa-se com a água "dissipada" no cultivo, pastagens, madeira, etc.

Alier (2013) menciona também sobre o índice físico - Pegada Ecológica - elaborado dentro da economia ecológica que tem tido bastante aceitabilidade. Este índice representa os impactos, rastros deixados pelas atividades econômicas no meio ambiente. Os cálculos do índice Pegada Ecológica em hectares globais são utilizados para as cidades ou regiões metropolitanas até mesmo para países. Terra degradada ou consumida (por exemplo, aquela sob áreas construídas), terra sob jardins, terra agrícola, área usada para pastagens, "terra de energia" - área verde que deve ser liberada para absorção do CO2 emitidos e área media para produzir um determinado fluxo de energia de biomassa equivalente ao fluxo atual obtido com a queima de combustíveis fósseis, finalmente a área de florestas para fornecer recursos naturais, todos são fatores que devem ser considerados na mensuração da Pegada Ecológica.

A Pegada Ecológica é criticada por acrescentar o uso efetivo do solo (por exemplo, um hectare por pessoa, por alimento e assim por diante) e pela utilização da terra em termos "virtuais" em relação à absorção pela fotossíntese do dióxido de carbono produzido pela queima de combustíveis fósseis. Por muitas vezes os resultados serem declarados em termos de quantos planetas reais mais virtuais a humanidade está usando, sendo que está análise depende da quantidade de terra partilhada com outras espécies.

\section{CONSIDERAÇÕES FINAIS}

Nestes dois últimos séculos observam-se transformações significativas ligadas ao crescimento econômico, que alteraram fortemente o estilo de vida da sociedade em prol do consumo. Nesse sentido, considera-se que tais transformações surtiram efeitos diretos sobre a relação economia e meio ambiente, onde o sistema econômico e a maneira irracional de crescimento são os grandes responsáveis por mudanças antagônicas ao sistema ecológico. 
Neste contexto reconhece-se que o sistema econômico se encontra introduzido em um sistema mais complexo e maior, que dar suporte para seu desenvolvimento, mas que também seus recursos são finitos e possuem inúmeras fragilidades. Com isso, reconhece-se a iminência de medidas que possibilite proteger os ecossistemas, um objetivo que pode ser alcançado através de caminhos que introduzam novos paradigmas e leituras sobre as relações economia-natureza.

Paradigmas de desdobramentos de estudos de valoração ambiental, sendo que o valor possui diversas dimensões, e que, os estudos sobre essas abordagens na economia precisam avançar e ganhar novos embasamentos. Pois, é imprescindível mais pesquisas sobre as relações fundamentais de valores que interagem no meio ambiental, social e econômico.

Seguindo esta linha Fernandez (2011) reflete que em meio a inúmeros valores o imprescindível é a conservação da biodiversidade, onde esta não é entendida em sua totalidade no sentido antropocêntrico e utilitarista, direto ou indireto, mas sim de acordo com os princípios ecológicos, ou seja, respeitando a resiliência ecossistêmica em escala global.

O caminho teórico teve como viés de inter-relação da economia com a ecologia e sociedade, apresentou-se como um percurso inovador, mas ao mesmo tempo desafiador, contudo sabe-se que o processo de pesquisa aparece com um leque de opções e dilemas.

Considerou-se que para se alcançar novos conceitos e maneiras de entender as interações entre os sistemas sociais, ecológicos e econômicos voltados para gestão ambiental é preciso superar barreiras paradigmáticas dessas ciências, por isso nesse desafio é necessário buscar novas certezas, ou quem sabe novas incertezas, embora considerando que essas novas certezas ou incertezas são relações da construção do conhecimento que poderão impulsionar o desenvolvimento do entendimento entre as novas posturas da economia, por meio do conhecimento e pesquisa da ciência ecológica e social.

\section{REFERÊNCIAS}


ALIER, J. M. Ecological economics, ICTA, Universitat Autònoma de Barcelona / FLACSO, Quito, Ecuador, 2013.

ANDRADE, D.C.; ROMEIRO, A.R. Serviços ecossistêmicos e sua importância para o sistema econômico e o bem-estar humano. Texto para discussão. Instituto de economia, UNICAMP, n.155, fev. 2009. Disponível em:

http://www.eco.unicamp.br/publicações/textos. Acesso em: 07 mar. 2013.

BRASIL. Lei no 6.938, de 31 de agosto de 1981. Dispõe sobre a Política Nacional do Meio Ambiente, seus fins e mecanismos de formulação e aplicação, e dá outras providências. Brasília: Congresso Nacional, 1981.

CONAMA. Resolução CONAMA Nº01, de 23 de janeiro de 1986. Disponível

http://www.mma.gov.br/port/conama/res/res86/res0186.html. Acesso em 02 de fevereiro de 2016.

FAUCHEUX, S.; NOËL, J-F. Economia dos recursos naturais e do meio ambiente. Lisboa, Instituto Piaget, 1995.

FERNANDEZ, B. P. M. Ecodesenvolvimento, desenvolvimento sustentável e economia ecológica: em que sentido representam alternativas ao paradigma de desenvolvimento tradicional?. Desenvolvimento e Meio Ambiente, [S.1], v.23,jul.2011 Disponível em: < http://ojs.c3sl.ufpr.br/ojs/index.php/made/article/view/19246>. Acesso em: 31 Ago. 2015. doi:10.5380/dma.v23i0.19246002.

GALLOSO, L. B. Herramientas para la gestión ambiental em la zona costeiro-marina: El ordenamento territorial, la evaluación ambiental estratégica y la evaluación de impacto ambiental. Panamá, 2009. Disponível em http://web.pnuma.org/gobernanza/cd/Conferencias/4\%20Lunes\%2011/El\%200rdenamiento\%20Ambiental\%20territorial,. pdf. Acesso em 20 de dezembro de 2015.

MAIA, A. G.; ROMEIRO, A. R.; REYDON, B. P. Valoração de recursos ambientais: metodologias e recomendações. Texto para discussão. Campinas, março 2004. Disponível em: < http://www.eco.unicamp.br/publicações/textos $>$. Acesso em: 07 mar. 2013.

MAY, P. H. Avaliação integrada da economia do meio ambiente: propostas conceituais e metodológicas. In: ROMEIRO, A. R. et al. Economia do meio ambiente: teoria, políticas e a gestão de espaços regionais. Campinas: UNICAMP, 1996.

MINISTÉRIO DO MEIO AMBIENTE. Disponível em http://www.mma.gov.br/port/conama/res/res86/res0186.html. Acesso em 02 de fevereiro de 2016.

MOTTA, R. S. da. Economia ambiental. Rio de Janeiro, Fundação Getúlio Vargas, 2006.

MUELLER, C. C. Os economistas e as relações entre o sistema econômico e o meio ambiente. Brasília: Editora UNB, 2007.

ODUM, E.P, BARRET, G.W. Fundamentos de ecologia. São Paulo: Thompson learning, 2007.

ORTIZ, Ramon Arigoni. Valoração Econômica Ambiental. In: MAY, Peter Herman; LUSTOSA, Maria Cecília; VINHA, Valéria da. (org). Economia do meio ambiente. Rio de Janeiro, Campus, 2003.

PATTERSON, M. G. Ecological production based pricing of biosphere processes. Ecological Economics. Elsevier, New Zealand,v.41,2002,p.457-478.Disponível em:

http://citeseerx.ist.psu.edu/viewdoc/download?doi=10.1.1.194.8990\&rep=rep1\&type=pdf Acesso em: 26 de outubro. 2013..

RIVERO ORTEGA, R. Planificación Estratégica del Territorio, Inversión pública y bienestar, Encuentro Nacional e Internacional "Planificando la Argentina del Bicentenario", Centro Cultural Bicentenario. Ciudad Autónoma de Buenos

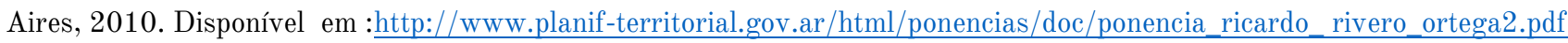


SINISGALLI, P. A. A. Emergia como indicador de valor para a análise econômica-ecológica. Megadiversidade, 2:18-23, 2006. 